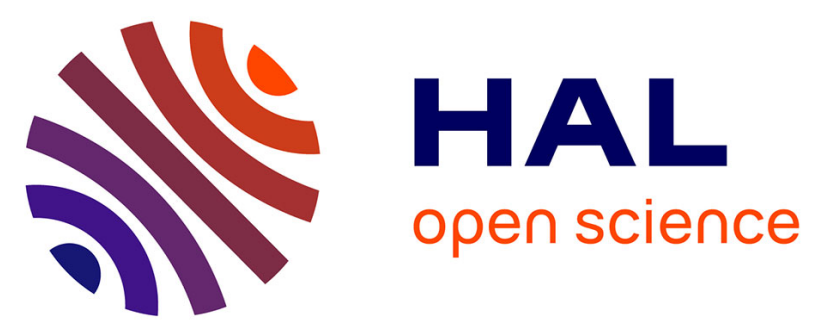

\title{
Characterisation of the hygro-thermo-mechanical behaviour of organic matrix composites instrumented with optical fibres: A study of interfacial bonding
}

\author{
H. Ramezani Dana, P. Casari, Rochdi El Abdi, S. Fréour, F. Jacquemin
}

\section{To cite this version:}

H. Ramezani Dana, P. Casari, Rochdi El Abdi, S. Fréour, F. Jacquemin. Characterisation of the hygro-thermo-mechanical behaviour of organic matrix composites instrumented with optical fibres: A study of interfacial bonding. International Journal of Adhesion and Adhesives, 2017, 77, pp.63-71. 10.1016/j.ijadhadh.2017.04.001 . hal-01518502

HAL Id: hal-01518502

https://hal-univ-rennes1.archives-ouvertes.fr/hal-01518502

Submitted on 5 May 2017

HAL is a multi-disciplinary open access archive for the deposit and dissemination of scientific research documents, whether they are published or not. The documents may come from teaching and research institutions in France or abroad, or from public or private research centers.
L'archive ouverte pluridisciplinaire HAL, est destinée au dépôt et à la diffusion de documents scientifiques de niveau recherche, publiés ou non, émanant des établissements d'enseignement et de recherche français ou étrangers, des laboratoires publics ou privés. 


\section{Author's Accepted Manuscript}

Characterisation Of The Hygro-ThermoMechanical Behaviour Of Organic Matrix Composites Instrumented With Optical Fibres: A Study Of Interfacial Bonding

H. Ramezani Dana, P. Casari, R. El Abdi, S. Fréour, F. Jacquemin

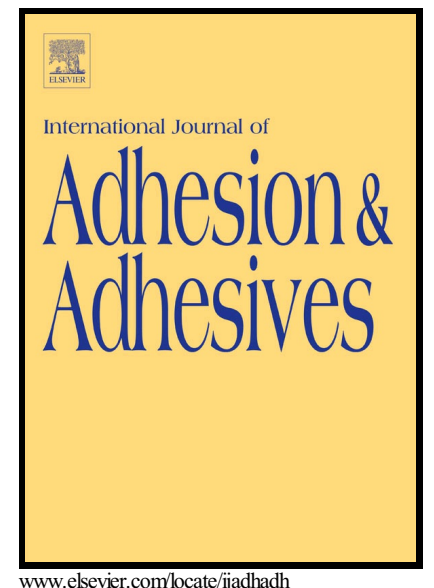

PII: S0143-7496(17)30081-7

DOI: $\quad$ http://dx.doi.org/10.1016/j.jadhadh.2017.04.001

Reference: JAAD2000

To appear in: International Journal of Adhesion and Adhesives

Received date: 14 November 2016

Accepted date: 21 March 2017

Cite this article as: H. Ramezani Dana, P. Casari, R. El Abdi, S. Fréour and F. Jacquemin, Characterisation Of The Hygro-Thermo-Mechanical Behaviour O Organic Matrix Composites Instrumented With Optical Fibres: A Study O: Interfacial Bonding, International Journal of Adhesion and Adhesives http://dx.doi.org/10.1016/j.jjadhadh.2017.04.001

This is a PDF file of an unedited manuscript that has been accepted fo publication. As a service to our customers we are providing this early version o the manuscript. The manuscript will undergo copyediting, typesetting, an review of the resulting galley proof before it is published in its final citable form Please note that during the production process errors may be discovered whic could affect the content, and all legal disclaimers that apply to the journal pertain 


\title{
CHARACTERISATION OF THE HYGRO-THERMO-MECHANICAL BEHAVIOUR OF ORGANIC MATRIX COMPOSITES INSTRUMENTED WITH OPTICAL FIBRES: A STUDY OF INTERFACIAL BONDING
}

\author{
H. Ramezani Dana ${ }^{1}$, P. Casari ${ }^{1}$, R. El Abdi ${ }^{2}$, S. Fréour ${ }^{1}$, F. Jacquemin ${ }^{1}$ \\ ${ }^{1}$ LUNAM Université - Université de Nantes - Centrale Nantes, Institut de Recherche en Génie Civil et \\ Mécanique (UMR CNRS 6183), 58 Rue Michel Ange, BP 420, 44606 Saint-Nazaire, France \\ ${ }^{2}$ Université de Rennes 1, IPR, Mécanique \&Verres, Campus de Beaulieu, 35042 Rennes Cedex, \\ France
}

"Corresponding author: Tel No: +33612808764.hossein.ramezani_dana@yahoo.com

\begin{abstract}
Moisture diffusion can decrease the mechanical stiffness and strength of organic matrix composites. Recently, Fibre Bragg Grating (FBG) sensors have been used in order to study the hygroscopic ageing of polyester/glass composites at room temperature. In the present study, the hygroscopic strain measurement of polyester /glass composite has been achieved at room temperature. Furthermore, measurements have been done at higher temperatures in order to better understand the combination of both hygroscopic ageing and varying temperatures on the mechanical properties of these composite samples. The Bragg wavelength $\left(\lambda_{b}\right)$ was found to shift linearly over a temperature range from room temperature to $35^{\circ} \mathrm{C}$. Beyond $35^{\circ} \mathrm{C}$, the Bragg wavelength does not linearly vary as a function of the temperature. A strong variation of the Bragg wavelength above a specific temperature threshold was found. This could be explained according to two mechanisms. Firstly, hygroscopic ageing could result in a decrease of the glass transition temperature $\left(T_{g}\right)$ of the polymer matrix. Therefore viscoelastic behavior may appear beyond this temperature. Hygroscopic ageing could also degrade the interfacial shear strength between the fibre and the resin. Differential Scanning Calorimetry (DSC) analyses showed that hygroscopic aging does not affect the Tg of the polyester resin. Furthermore, it has been found that the hygroscopic aging degrades the interfacial adhesion of the optical fibre/polyester according to the considerable decreases of the interfacial shear strength observed in practice.
\end{abstract}

Keywords. hygroscopic ageing, mechanical characterisation, interfacial bonding, optical fibre

\section{Introduction}

The organic matrix composites (OMC's) have been used widely in structural applications over the past three to four decades [1]. The service life of such structural components is strongly associated to their durability, which itself depends on the environmental conditions they are subjected to. Recently, the effects of humidity on the mechanical properties of polymer matrix composites have been reported by several authors [2-5]. Glass fibers and polyester resin, the two constituents of the composite samples used in this study, present heterogeneous hygroscopic properties. For example, the coefficient of moisture expansion $(\mathrm{CME})$ and the maximum moisture absorption capacity (Ms) are entirely different for these two materials. As a result of this, moisture absorption gives rise to the hygroscopic swelling 
of the matrix, which, coupled with the strong heterogeneity between the properties of both the matrix and the hydrophobic E-glass reinforcements, induces heterogeneous local stresses within the composite [6]. Considerable efforts have been made by researchers to develop analytical models that can predict the mechanical states occurring during both the transient stage and the permanent regime of the moisture diffusion process of organic matrix composites submitted to hygro-mechanical loads [7-8]. Several studies highlight that the resulting mechanical states bring along structural damage [9-11]. Therefore, the determination of internal mechanical states of polymer matrix composite submitted to the hygro-mechanical loads is critical for reliably predicting the long term behavior and durability of these composite structures. Different techniques have been developed in order to measure the hygro mechanical strain [12-13]. Recently, optical fibre sensors have been used to achieve the measurement of strain and temperature [14]. Optical fibre sensors provide many advantages compared to other strain measurement techniques, such as electrical and piezoelectric sensors, due to their ability to investigate the internal mechanical states within the bulk of the specimen [15-17]. The FBG is an optical filtering device that reflects light of a specific wavelength and is present within the core of an optical fiber waveguide. The reflected wavelength depends on the spacing of a periodic variation or modulation of the refractive index that is present. The sensing function of an FBG originates from the sensitivity of both the refractive index of the optical fiber and the grating period within the fiber to externally applied load and temperature. In the authors' previous study, the hygroscopic properties of glass/polyester composites have been identified by using FBG sensors [18]. Authors used FBG sensors in order to characterize the evolution of the hygroscopic strain field in unidirectional fibre reinforced composites, immersed in deionized water, during the moisture diffusion process. Materials properties such as the Coefficients of Moisture Expansion (CME) as well as the transverse diffusivity $\mathrm{D}_{2}$ were identified from the treatment of the collected data [19]. Additionally, the effect of temperature change on the Bragg wavelength $\left(\lambda_{b}\right)$, and consequently on the hygroscopic strain, was presented. In this study, the shift in the fiber Bragg wavelength $\left(\lambda_{b}\right)$ due to the influence of temperature has been examined for the glass/polyester composite specimen. It was observed that the response of Bragg wavelength shifting with temperature is linear over a range from $23^{\circ} \mathrm{C}$ to $35^{\circ} \mathrm{C}$. On the contrary, the Bragg wavelength does not exhibit same behavior beyond $35^{\circ} \mathrm{C}$. This could be explained by several phenomena. Among them, the two main factors are, firstly, the influence of the hygroscopic ageing of composite samples which could lead to a fall in $\mathrm{T}_{\mathrm{g}}$, and secondly, a viscoelastic behavior appearing at higher temperatures. Moreover, the absorbed water can induce the debonding of the fibre-resin interface.

For that purpose, the characterisation of the glass transition temperatures of elaborated polyester resin and acrylate coating before and after hygroscopic aging has been achieved. In addition, the determination of the interfacial debonding stress of the silica optical fibre/polyester interface before and after hygroscopic aging has been carried out using the single-fibre pull-out test.

\section{Materials and testing methods}

\subsection{Materials and specimens}

An ortho-phthalic polyester resin (POLYLITE 420-731) has been used in this study. The gelling point of this resin is relatively short (about $20 \mathrm{~min}$ ). Methyl Ethyl Ketone Peroxide (MEKP) has been used as a catalyst for initiating the polymerization of this polyester resin. The employed optical fibres are standard SMF-28e single mode fibres with a $250 \mu \mathrm{m}$ 
diameter. This fibre is composed of a silica core and an acrylate coating. The acrylate coating is often used in standard optical fibres in order to protect the silica fibre core. Despite having a hydrophilic behavior, it ensures the protection of fibre against micro-bending and external physical stresses. The optical fibres used in this study were supplied by IX-fiber (SMF28N/A- $0.4 \mathrm{~m}$ ). The polyester resin/optical fibres samples have been manufactured by a fairly simple method. In this method, a metallic mold, which consists of two steel plates, has been employed. The optical fibres have been placed between two plastic chocks - themselves covered by rubber gaskets (Figure 1A). The gaskets have the role of protecting the optical fibre against external stress, and consequently prevent fibre breakage. The metal mold was placed into an environmental chamber and heated up close to $50^{\circ} \mathrm{C}$ in order to reduce the temperature gradient between the mold and polyester resin. The prepared resins were then transferred into the mold and kept in an environmental chamber for 4 hours at ambient temperature $\left(23^{\circ} \mathrm{C}\right)$. After polymerization, the optical fibre/resin specimens were withdrawn from environmental chamber and cut in order to carry out the pull-out test. After cutting and polishing, the specimen surfaces were cleaned with ethanol in order to remove any residual oil and dirt resulting from milling operation. The final dimensions of the specimens prepared for the pull-out test stated below were $(25 \times 10 \times 2) \mathrm{mm}^{3}$. A series of specimens, some containing optical fibres, and others without the fibres, were used for the ageing tests.
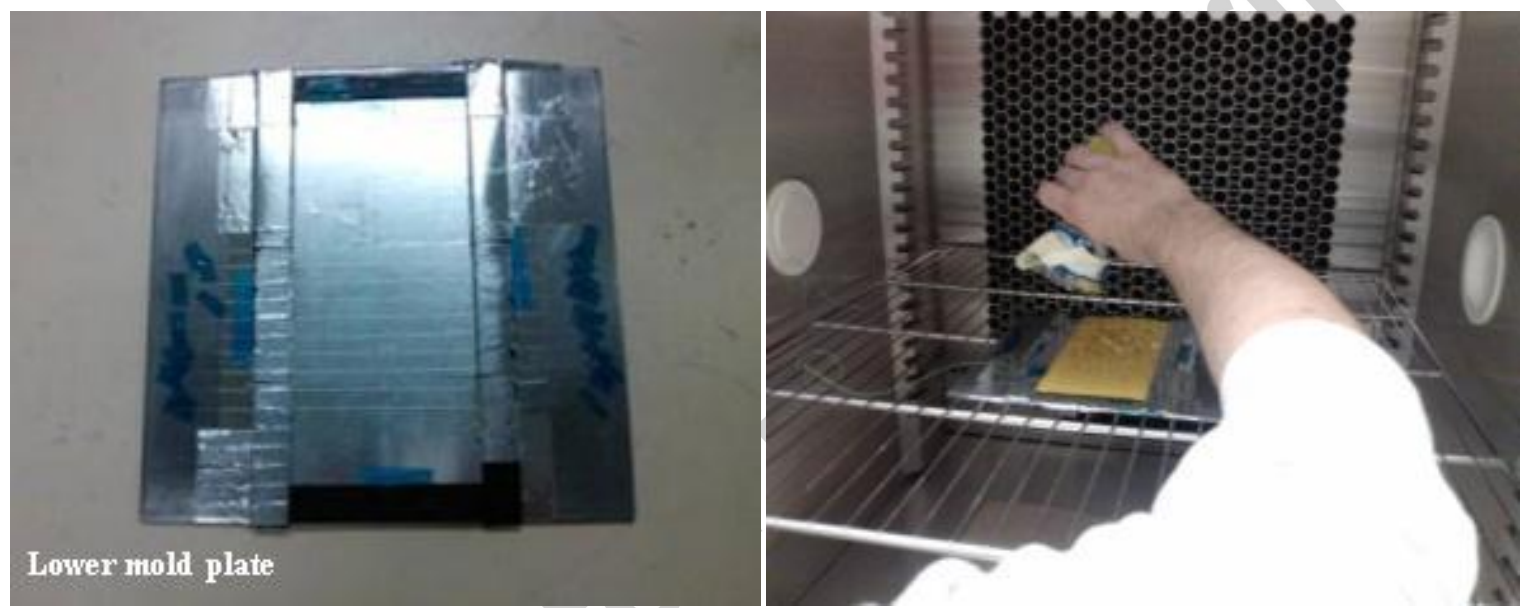

Figure1. Preparation of mold plate (A) and mold position in the heating chamber (B).

The tested unidirectional composite samples were made of $\mathrm{E}$ glass fibres embedded in an ortho-phthalic polyester (POLYLITE 420-731). The specimens were manufactured through the vacuum assisted resin infusion (VARI) method. Several composites, as well as neat resin square plates $\left(1.3 \mathrm{~mm}\right.$ thick) were fabricated. The fibre volume fraction $\left(\mathrm{v}_{\mathrm{f}}\right)$ of the elaborated composites varied from $17 \%$ to $22 \%$. The initial weights and dimensions of the specimens were recorded. The FBGs employed in this study were printed on standard SMF-28e single mode optical fibres with a $250 \mu \mathrm{m}$ diameter. Bragg gratings (10 mm long) were uniform, and centered on a $1555 \pm 0.2 \mathrm{~nm}$ wavelength. The use of FBGs in composite samples is limited by the ability to insert these sensors in these materials (so as to retrieve the optical signal) whilst minimizing their effect on the composites mechanical behavior. In order to address this issue, the optical fibre containing Bragg grating was inserted between two plates, bonded by polyester resin. The FBGs were either aligned with the reinforcing fibres or set perpendicularly to them. In the area of the grating, the acrylate coating was removed from the FBG in order to get the most direct strain provided by the surrounding material. The final size of the obtained instrumented samples is $90 \times 90 \times 3 \mathrm{~mm}^{3}$. In addition, this kind of architecture enables us to limit the stresses experienced by optical fibres during the fabrication process. Two series of specimens were manufactured. The first subset of samples were equipped with 
FBGs sensors. This group of samples was intended to provide the time-dependent evolution of the internal strain states throughout the moisture diffusion process. The second subset of specimens, which did not contain any Fibre Bragg Grating, were devoted to moisture uptake characterization by means of periodic mass measurements. These samples have the same final size as the instrumented specimens $\left(90 * 90 * 3 \mathrm{~mm}^{3}\right)$. The experimental conditions that these samples were subjected to (with regards to the hygroscopic ageing process) is detailed in the next section.

\subsection{Hygroscopic ageing process}

\subsubsection{Moisture absorption experiments}

The hygroscopic ageing tests were carried out on both the composite and neat resin samples in order to identify their diffusive behavior. The initial weights of the samples were recorded. Thereafter, the specimens were immediately placed into deionized water maintained at controlled ambient temperature $\left(20{ }^{\circ} \mathrm{C}\right)$. The change in mass was measured using an analytical electronic scale, marketed by SARTORIUS ${ }^{\circledR}$, with an accuracy of $0.1 \mathrm{mg}$. The weight gain versus the square root of time $(\sqrt{\boldsymbol{t}})$ curves for the composite and neat resin samples were then determined in order to follow their moisture absorption kinetics. The results (detailed in paragraph 3.1) show that the studied samples exhibit a Fickian diffusive behavior.

\subsubsection{Identification of moisture diffusion parameters}

The identification method used in this study for determining the diffusion parameters was explained in a previous work [19]. This numerical method was intended for identifying both the macroscopic transverse moisture diffusion coefficient $\left(\mathrm{D}_{2}\right)$ and the maximum moisture absorption capacity $\left(\mathrm{M}_{\mathrm{s}}\right)$ of the samples. The numerical method was based on the comparison between the 3D Fick's solution and the experimental measurement of the weight gain occurring during the diffusion process [20]. The method consists of finding out the unknown values of the problem by minimizing the standard deviation $\boldsymbol{q}$ (Equation 1) using a GaussNewton algorithm:

$$
\boldsymbol{q}=\sum_{i}\left[\boldsymbol{M}\left(\boldsymbol{t}_{\boldsymbol{i}}\right)-\boldsymbol{M}_{i}\right]^{2}
$$

Equation 1

where $\boldsymbol{M}\left(\boldsymbol{t}_{\boldsymbol{i}}\right)$ is the moisture content calculated at time $\boldsymbol{t}_{\boldsymbol{i}}$ from the analytical solution to Fick's model, whereas $\boldsymbol{M}_{\boldsymbol{i}}$ is the corresponding experimental point.

\subsection{Hygroscopic strain measurement method}

FBG sensors have been used in order to achieve local strain measurements [21-23]. As mentioned previously, in the area close to the grating, the FBGs acrylate coating was removed in order to directly get the strain experienced by the surrounding composite. The acrylate coating could actually induce many side problems such as fibre matrix debonding. Moreover, it interferes with the local strain measurement due to the heterogeneous properties of acrylate compared to the composite. The diffusivity, maximum moisture absorption and coefficients of moisture expansion are different from one material to the other, requiring careful posttreatment of the experimental data gathered whenever the acrylate coating cannot be removed. However, the instrumented samples prepared in the present work enable us to directly determine the time-dependent evolution of the local internal axial strain states experienced by the optical fibre throughout the moisture diffusion process. Since the internal strains of the 
optical fibre are strongly related to the distribution of the mechanical states in the embedding material, this sensor provides the data necessary to characterize the local strain experienced by the composite surrounding the optical fibre. The principle of local strains measurement through FBGs has been presented in various articles [13, 15, 24]. An FBG consists of a series of grating slices formed along the fibre axis. If the Bragg condition is fulfilled, a light signal propagating into the device can interfere constructively with the waves reflected by each of the slices. Consequently, a back reflected signal with a center wavelength commonly known as the Bragg wavelength $\left(\lambda_{b}\right)$ is formed. The Bragg wavelength $\left(\lambda_{b}\right)$ depends on the effective index of refraction $\left(\boldsymbol{n}_{\boldsymbol{e f f}}\right)$ and on the Bragg period $(\Lambda)$ of the grating according to the wellknown Bragg equation:

$$
\lambda_{b}=2 n_{e f f}^{\Lambda}
$$

Equation 2

In the case where the FBG is submitted to a homogeneous axial strain $\varepsilon_{z}$ and uniform temperature change $\Delta T$, the Bragg wavelength experiences a deviation $\left(\Delta \lambda_{b}\right)$ from the reference value $\left(\lambda_{b 0}\right)$ corresponding to the unloaded state $\left(\varepsilon_{z}=0 ; \Delta T=0\right)$ :

$$
\frac{\Delta \lambda_{b}}{\lambda_{b}}=\frac{\lambda_{b-} \lambda_{b 0}}{\lambda_{b}}=\boldsymbol{a} \cdot \varepsilon_{z}+\boldsymbol{b} . \Delta T \quad \text { Equation } 3
$$

Coefficients $a$ and $b$ depend on the nature of the optical fibre and the FBG printing parameters.

Some preparatory tests have been carried out on the optical fibres (before the instrumentation of the composite specimens) at various controlled environmental conditions, thus permitting the characterisation of the FBGs sensitivity parameters, namely $a=7.8^{*} 10^{-6} /{ }^{\circ} \mathrm{C}$ and $b=0.78 * 10^{-6} /(\mu \mathrm{m} / \mathrm{m})$, respectively.

According to relation (3), under isothermal conditions, the Bragg wavelength shift $\lambda_{b}$ is proportional to the axial strain $\left(\varepsilon_{z}\right)$. According to Eq (3), one obvious major limitation of FBG sensors in composites is their simultaneous sensitivity to both deformation and temperature. As a result, in order to measure moisture absorption through strain variation, the temperature must be separately measured. This process allows thermo-optical effects, and thus thermomechanical deformations, to be deduced as a result the Bragg wavelength shifts caused by strains due to moisture absorption only. In the practical case considered in this work, the measured Bragg wavelength shift enables the strain experienced in the center of the instrumented samples to be determined from relation 3 relative to the value of interest; namely, the product $a . \varepsilon_{z}$. The Bragg wavelength shifting is recorded at ambient temperature $\left(23^{\circ} \mathrm{C}\right)$ in order to investigate the effect of hygroscopic ageing. The measured Bragg wavelength is plotted as a function of water uptake for the composite specimens. As an example, the measured Bragg wavelength shift $\left(\lambda_{b}\right)$ for the samples containing $17 \%$ fibres equipped with FBGs positioned perpendicularly $\left(90^{\circ}\right)$ and/or parallel $\left(0^{\circ}\right)$ to the reinforcing fibres are $5.03 \mathrm{~nm}$ and $0.27 \mathrm{~nm}$ respectively. From relation (3), assuming that the thermal contribution $(b . \Delta T)$ is negligible, hygroscopic strain values close to $4160 \times 10^{-6}$ and $260 \times 10^{-}$ ${ }^{6}$ have been found in the two principal directions.

\subsection{Measurement of the Glass Transition Temperature $T_{g}$}

In order to determine the glass transition temperature $\left(T_{g}\right)$ of elaborated samples before and after hygroscopic ageing, we applied the Differential Scanning Calorimetry (DSC) method. In this research work, a METTLER TOLEDO-STARe-DSC was used to measure the 
temperature and heat flows associated with thermal transitions in the elaborated resin samples. All prepared DSC samples had a mass of less than $20 \mathrm{mg}$. The samples were heated from room temperature $\left(25^{\circ} \mathrm{C}\right)$ to $300^{\circ} \mathrm{C}$ at a rate of $20^{\circ} \mathrm{C} \mathrm{min}^{-1}$.

\subsection{Characterization of the interfacial bonding stress}

\subsubsection{Interfacial shear strength measurement}

Pull-out tests have been achieved in order to characterize the interfacial bonding stress of the optical fibre/ resin samples. It is necessary to recall that the pull out tests were done on the bare fibres.

The pull out tests were performed at the IPR laboratory (Département Mécanique \& Verres) at "Université de Rennes 1". The pull out tests were carried out on a LLOYD LR $50 \mathrm{~K}$ universal testing machine equipped with a force sensor of $100 \mathrm{~N}$. Prior to the test, the base of the optical fibre/resin samples were fixed by lower jaw clamp. The optical fibre that comes out of the resin sample was wrapped around a pulley with a radius of $0.2 \mathrm{~m}$. The upper pulley is mobile and subject to a constant imposed strain rate (here the selected strain rate is equal to $\left.0.04 \mathrm{~min}^{-1}\right)$. An automatic acquisition system enables the force and displacement data to be backed up in real time. At the end of the test, the matrix and fibres are collected in order to measure the embedded length $\left(\mathrm{L}_{\mathrm{e}}\right)$ and study the microstructure by Scanning Electron Microscopy (SEM).

\subsubsection{The principles of the pull out test}

Initially, this test was developed on fibres surrounded by a polymer matrix [25], before being used in Organic Matrix Composites. The principle of this test consists of submitting a fibre to mechanical loading. One end of the fibre is embedded in a matrix, and the other end is exposed to an increasing uniaxial tensile stress (Figure 2a) until decohesion at the interface occurs and, subsequently, the complete extraction of the fibre is achieved. Often, the curve of applied force versus displacement is plotted in order to analyze the experimental results (Figure 2b). The obtained curve can be divided into three areas. The first zone (A) corresponds to the elastic strain of the free part of the fibre and to interfacial debonding. Here, the maximum force $\left(F_{d}\right)$ corresponds to the entire fibre debonding from the matrix. Decohesion is followed by a sudden drop of the debonding force from $F_{d}$ to $F_{0}(\mathrm{~B})$. Subsequently, the fibre extraction process starts from the force $F_{0}$, involving friction between the fibre and the matrix [domain (C)] [26]. 


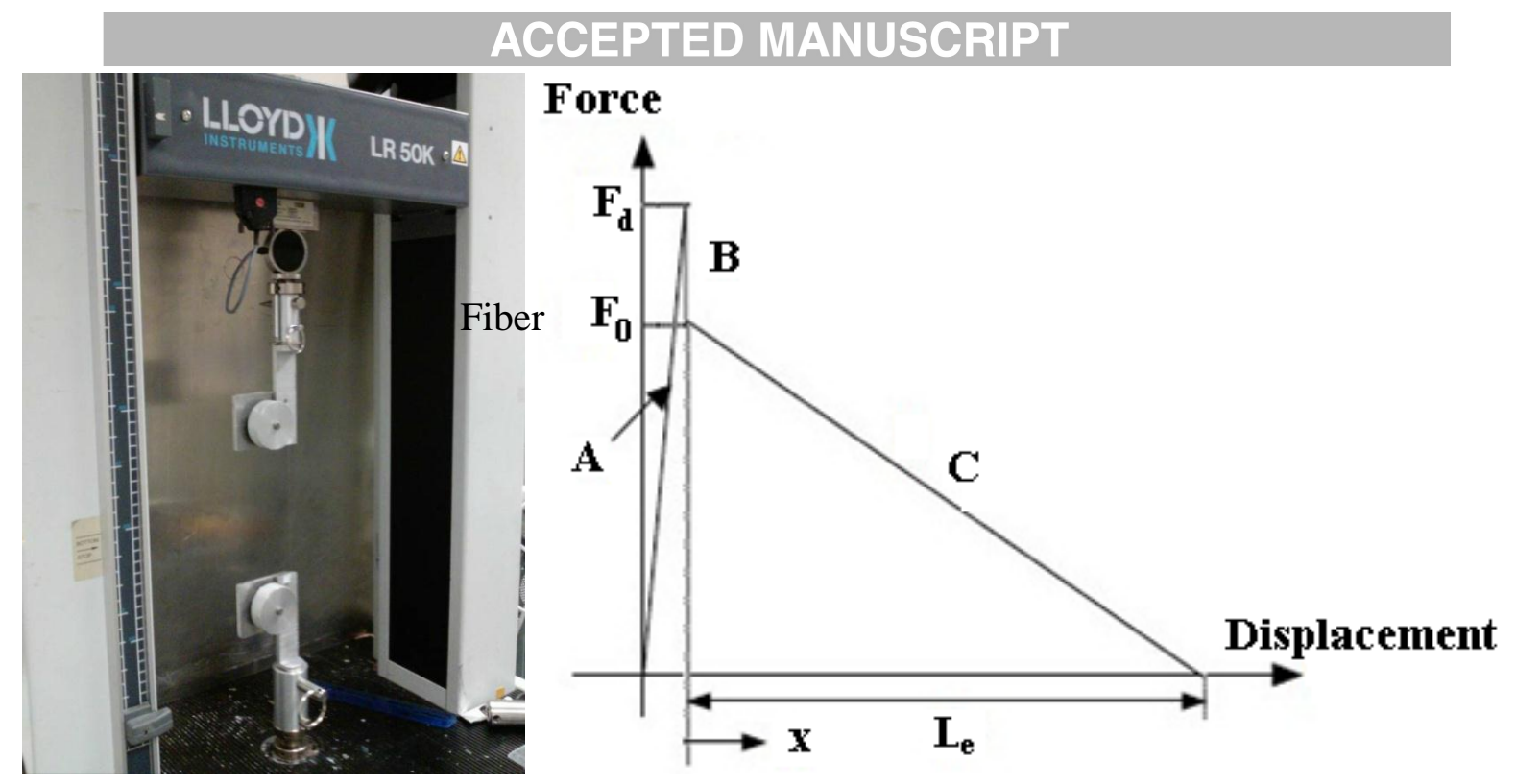

Figure 2.Tensile testing device (a) and typical curve of pull-out test (b)

The value of the interfacial shear strength can be determined from the following equation:

$$
\tau_{d}=\frac{F_{d}}{2 \pi R L_{e}} \quad \text { Equation } 4
$$

According to Equation 4, $\left(\tau_{d}\right)$ is expressed as a function of the embedded length $\left(L_{e}\right)$, the debonding force $\left(F_{d}\right)$ and the radius of the fibre $(R)$. The value of the debonding force $\left(F_{d}\right)$ can be determined from the applied load-displacement curve. In the present study, the embedded length $\left(L_{e}\right)$ of inserted fibre in the matrix has been measured through optical microscopy.

\section{Results and discussion}

\subsection{Moisture uptake}

Figure 3 shows the evolution of the moisture uptake as a function of the square root of time, obtained for the three glass fibre-polyester composite samples containing a volume fraction of the fibre equal to $17 \%, 21 \%$ and $22 \%$ respectively. As one can see from figure 3(a), the three samples exhibit an almost linear evolution of the moisture uptake for several months until a pseudo-plateau - indicating that the saturation of the diffusion process has been reached. The curve of weight gain versus the square root of time obtained for the neat polyester resin sample is shown on Figure 3 (b). 


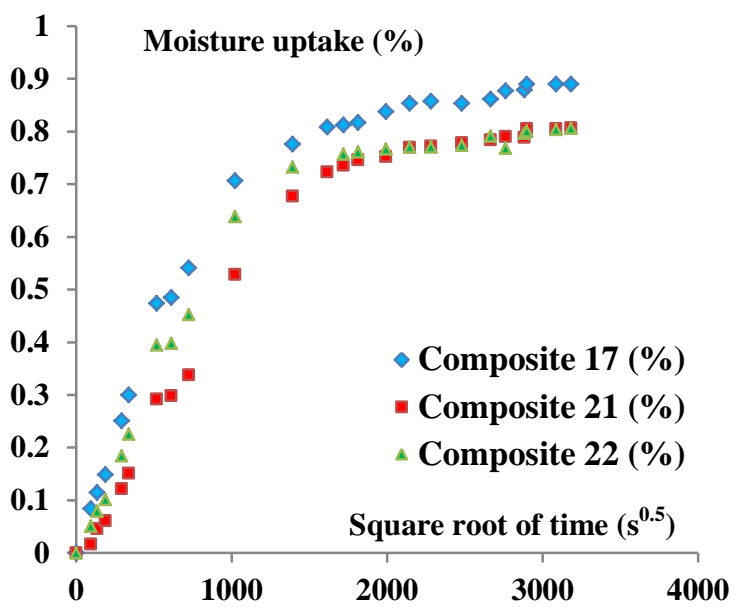

(a)

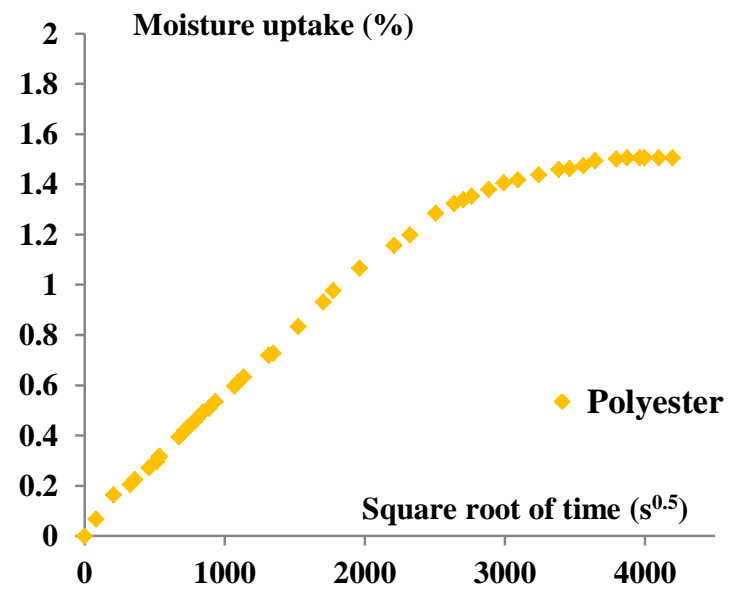

(b)

Figure 3. Moisture absorption curves for (a) glass fibre - polyester composite samples and (b) neat polyester resin sample.

It can be noted that these samples present a Fickian diffusion behavior. According to figure 3, the maximum moisture absorption capacity of the neat polyester is nearly twice more that of the composite specimens ( $1.5 \%$ versus $0.78 \%$ respectively).

The diffusion kinetics of the polyester resin (with and without optical fibres) have been determined using the same gravimetric test. This was intended to assess the possible effect of the acrylate coating on the moisture absorption process in the studied samples. The computed evolutions obtained through the identified diffusive parameters found using Fick's model were plotted on the same graph as the experimental data collected on the resin samples (Figure 4). Figure 4 enables us to evaluate the reliability of the identification method.

\section{Moisture uptake (\%)}

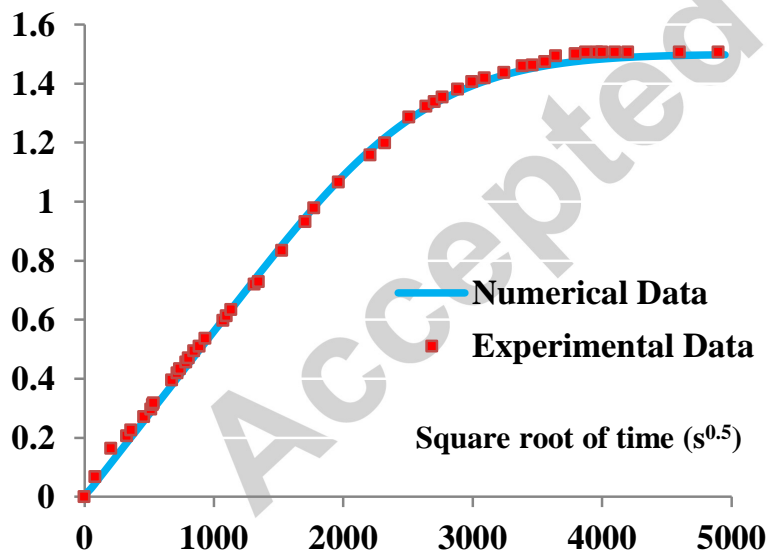

(a)
Moisture uptake (\%)

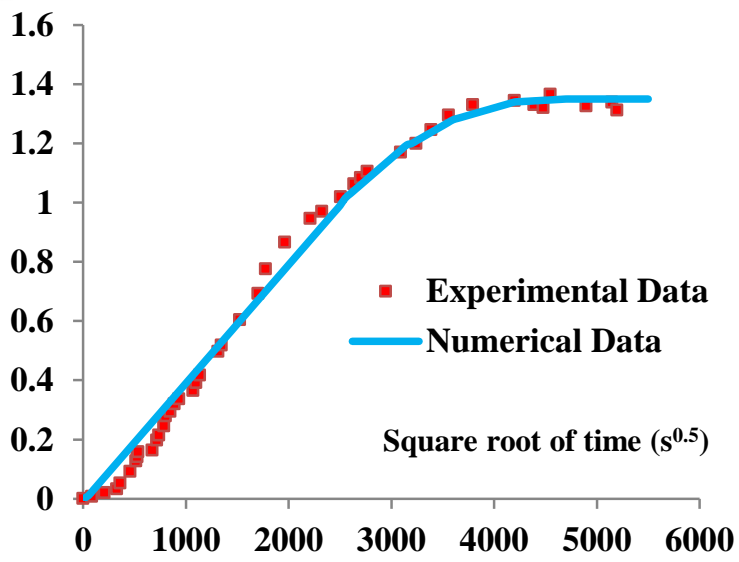

(b)

Figure 4. Experimental and numerical (Fick model) curves of moisture uptake for neat polyester specimens with (a) and without (b) optical fibres. 


\section{ACCEPTED MANUSCRIPT}

The moisture diffusion parameters of composites, neat polyester resin samples are summarised up in Table 1:

Table 1. Moisture diffusion parameters of studied samples from the collected experimental gravimetric study.

\begin{tabular}{ccc}
\hline & $\begin{array}{c}\text { Transverse moisture } \\
\text { diffusion parameter } \\
\mathrm{D}_{2}\left(\mathrm{~mm}^{2} / \mathrm{s}\right)\end{array}$ & $\begin{array}{c}\text { Maximum moisture } \\
\text { absorption capacity } \\
\mathrm{M}_{\mathrm{S}}(\%)\end{array}$ \\
\hline Composite $17 \%$ & $2.07 * 10^{-7}$ & 0.85 \\
Composite $21 \%$ & $1.74 * 10^{-7}$ & 0.78 \\
Composite $22 \%$ & $1.97 * 10^{-7}$ & 0.79 \\
Neat polyester resin with optical fibre & $2.31 * 10^{-7}$ & 1.51 \\
Neat polyester resin & $2.07 * 10^{-7}$ & 1.31 \\
\hline
\end{tabular}

\subsection{Hygroscopic strain measurement}

The measured Bragg's wavelength shift enables the strain experienced in the center of the instrumented samples to be determined from relation (3), assuming that the thermal contribution, namely, the product $b . \Delta T$ is negligible by comparison to the quantity of interest: a. $\varepsilon_{z}$. The Bragg wavelengths from before and after ageing and the corresponding strains for all tested samples were gathered in Table 2 .

Table 2. Hygroscopic strain for all instrumented specimens.

\begin{tabular}{ccccccc}
\hline $\mathrm{v}_{\mathrm{f}}(\%)$ & Angle $\left(^{\circ}\right)$ & $\begin{array}{c}\lambda_{b}(\mathrm{~nm}) \text { Before } \\
\text { immersion }\end{array}$ & $\begin{array}{c}\lambda_{b}(\mathrm{~nm}) \text { After } \\
\text { immersion }\end{array}$ & $\begin{array}{c}\lambda_{b} \\
(\mathrm{~nm})\end{array}$ & $\varepsilon\left(10^{-6}\right)$ & $\begin{array}{c}\mathrm{CME} \\
(\beta)\end{array}$ \\
\hline 17 & 0 & 1554.68 & 1554.95 & 0.27 & 255 & 0.021 \\
17 & 90 & 1550.98 & 1556.01 & 5.03 & 4157 & 0.471 \\
21 & 0 & 1554.68 & 1555.14 & 0.46 & 379 & 0.042 \\
21 & 90 & 1551.48 & 1555.93 & 4.45 & 3677 & 0.397 \\
22 & 0 & 1554.68 & 1554.97 & 0.29 & 239 & 0.026 \\
22 & 90 & 1550.81 & 1555.18 & 4.37 & 3611 & 0.397 \\
\hline
\end{tabular}

It has been shown that the effect of temperature variations on the measured strain is significant. Therefore, the determination of purely hygroscopic strain requires a correction, particularly in the direction parallel to the reinforcing fibres. Various studies have been achieved in order to separate the purely hygroscopic strain from the temperature effect on the FBG measurement [27-29]. We propose a reliable method in order to correct the temperature effects before estimating the hygroscopic strains. This method is based on the analysis of the strain change experienced by the material due to a thermal loading once the aged specimens have reached a saturated state. On the basis of this technique, the effects induced by the temperature change from those of the hygroscopic strain on the measured Bragg wavelength shifting $\left(\lambda_{b}\right)$ have been separated by plotting the Bragg wavelength as a function of temperature (Fig. 5). It should be remembered that the response of Bragg wavelength shifting to the temperature is linear over a range from $23^{\circ} \mathrm{C}$ to $35^{\circ} \mathrm{C}$. 


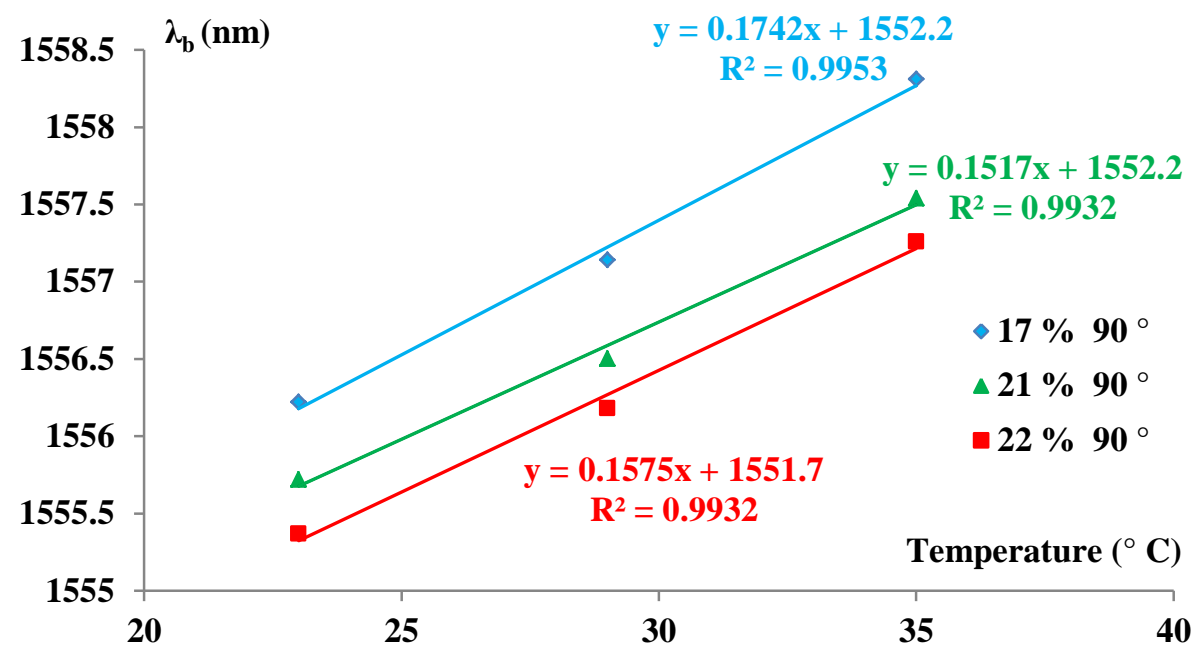

Figure 5. Bragg wavelength as a function of temperature for the composite specimens instrumented perpendicularly to the reinforcing fibres.

In the present study, the Bragg wavelength shifting is recorded at higher temperature in order to investigate the effect of hygroscopic ageing, simultaneously with temperature. The measured Bragg wavelength is plotted as a function of temperature on Figure 6 for the composite specimens instrumented by FBG positioned perpendicularly (Figure 6a) or parallel (Figure 6b) to the reinforcing fibres, respectively.
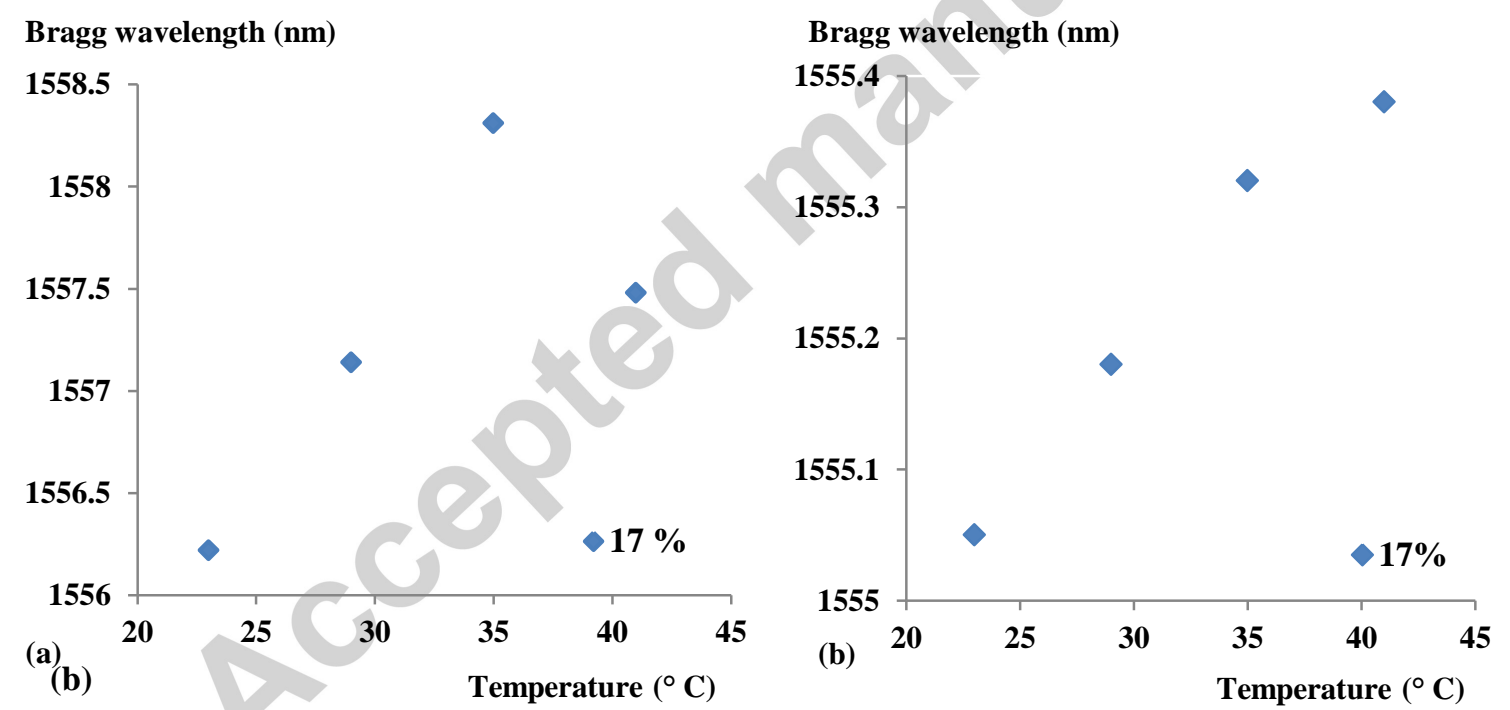

Figure 6. Bragg wavelength as a function of temperature for the polyester based composite specimens instrumented perpendicularly (a) and parallel (b) to the reinforcing fibres.

We could find that beyond $35^{\circ} \mathrm{C}$, the Bragg wavelength does not linearly vary as a function of the temperature anymore. The latter event could be due to multiple phenomena. This reaction could be explained in two ways. Firstly, by the influence of the hygroscopic ageing of composite samples which could have led to a fall of $T_{g}$ and secondly, by a viscoelastic behavior appearing a higher temperatures. Moreover, the absorbed water can induce the debonding of the fibre-resin interface [30]. Thus, another possible explanation could come from the hygroscopic stress induced by absorbed moisture. In this case, when the mechanical states exceed the interfacial debonding stress of silica optical fibre-resin system, such nonlinearities as observed on figure 6 could happen. It should be noted that the hygroscopic 
stress could be coupled with the fall of the glass-transition temperature. According to figure 6 , this effect occurs in both types of composite samples where FBGs were located perpendicular and parallel to the reinforcing fibres. As a result, we propose the characterization of the glass transition temperature of elaborated polyester resin and acrylate coating before and after hygroscopic aging. On the other hand, the determination of interfacial debonding stress of silica optical fibre/polyester seems to be relevant for properly interpreting the obtained results. The characterization of that property will be handled by using the single-fibre pull-out test before and after hygroscopic ageing.

\subsection{The glass-transition temperature measurement}

Differential scanning calorimetry (DSC) analysis reveals information on the glass transition temperature $\left(T_{g}\right)$ and degree of cure. For the thermosetting resins, the $T_{g}$ could be determined from the inflection point of the curve plotting the first derivative of the heat capacity as a function of temperature. Figure 7 (a) represents the DSC curves of the glass polyester composite specimens before hygroscopic ageing. The thermogram shows that the $T_{g}$ of composite specimens with different fibre contents is almost identical, with an average value of $50^{\circ} \mathrm{C}$. An exothermic peak appears on the DSC thermograms of figure 7a. This means that the whole crosslinking, and therefore the entire hardening of the resin, was not fully achieved for these composite samples. It is important to note that in cross-linked systems, the glass transition temperature depends on the reticulation degree: it shifts to higher temperatures when the reticulation degree increases. The thermograms of polyester resin and acrylate coating in un-aged state are presented in figure 7(b). The thermograms highlight that the neat polyester resin has a glass transition temperature near to the $\mathrm{Tg}$ of glass polyester composite specimens (about $55^{\circ} \mathrm{C}$ ). The thermograms indicate that the polyester resin has a lower glass transition temperature than the acrylate resin $\left(55^{\circ} \mathrm{C}\right.$ versus $160^{\circ} \mathrm{C}$, respectively). We could also observe the same exothermic peak on the polyester resin thermogram, as on the other composites thermograms.
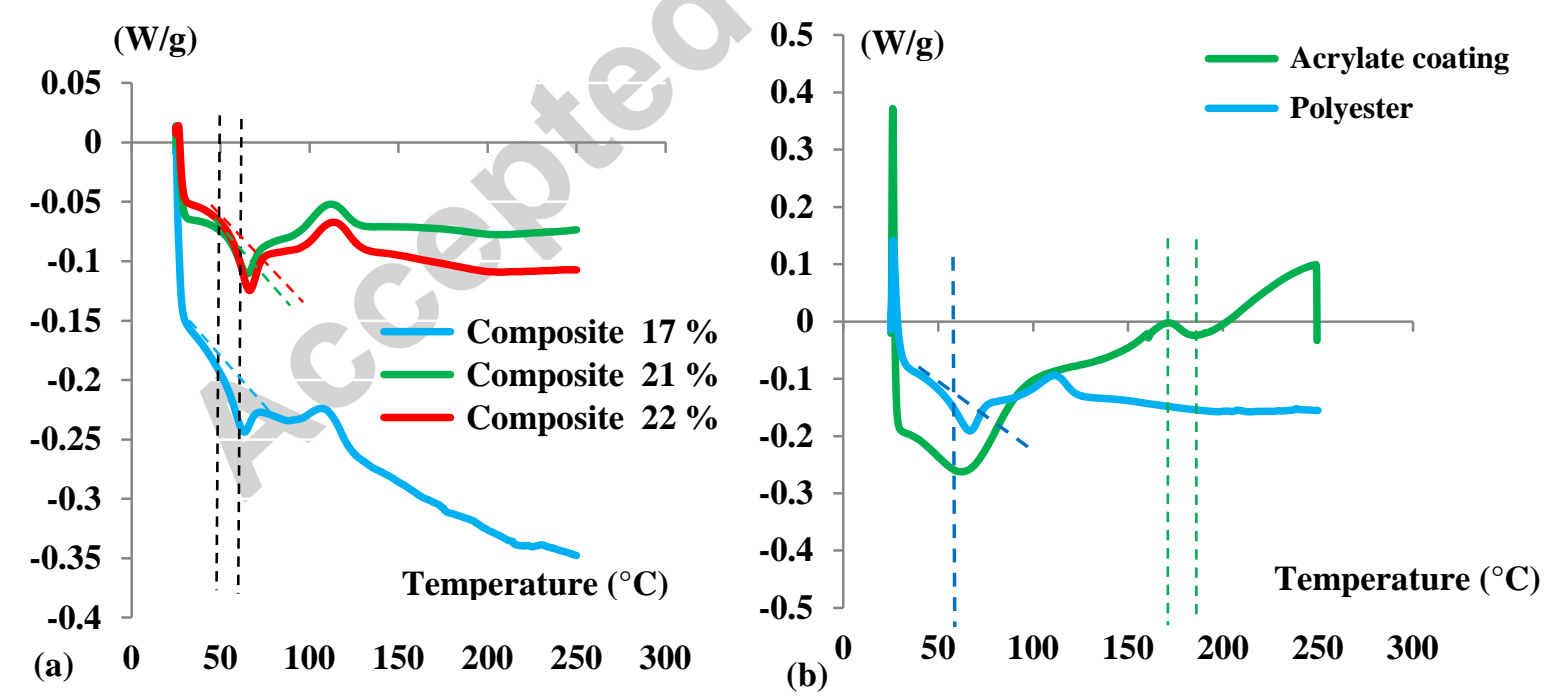

Figure 7. Glass transition temperature of composite samples (a) and resin samples (b) before hygroscopic aging.

We can also indicate that the acrylate glass transition temperature is considerably more important than in the polyester resin. Figure 8 represents the thermograms of polyester samples before and after hygroscopic ageing. Knowing that the determination of the $T_{g}$ could 
be difficult after ageing, we studied the effect of hygroscopic ageing on the three polyester specimens. The latter helps to improve the reliability of the obtained results. We found a very good reproducibility of the obtained results in non-aged and aged states for polyester resins. It can therefore be observed in figure 8 that hygroscopic ageing did not significantly affect the $T_{g}$ of polyesters (with an average value of $56^{\circ} \mathrm{C}$ after ageing). Some authors have reported a fall of $T_{g}$ during hygroscopic ageing which could vary from $10^{\circ} \mathrm{C}$ up to $80^{\circ} \mathrm{C}$ approximately [31-35]. For the unsaturated polyester resins, $T_{g}$ is expected to decrease considerably beyond $1 \%$ of absorbed water. However, this event is not observed in our study. Nevertheless, the exothermic peak height of the DSC thermogram decreases when the polyester experiences humid aging. This phenomenon is due to the increasing of the degree of polymerisation during the hygroscopic ageing, but it doesn't seem to significantly affect the $T_{g}$ in the present case. The transition temperature of polyester after aging, measured in this study, has been compared with the Tg of aged polyester predicted by the Fox law. We could note that in this case the two values $\left(54.1^{\circ} \mathrm{C}\right.$, predicted by the Fox equation and $56.0^{\circ} \mathrm{C}$, according to DSC measurements) are in reasonable agreement.

It has been shown that the presence of fibres, and consequently the presence of interfaces, enhances the plasticisation of the composite matrix, in comparison with pure resin samples, and slows down the $T_{g}$ kinetics [31]. Unfortunately the obtained results on the aged acrylate sample are not exploitable. In fact, the thermogram corresponding to this sample shows just an intense peak representing an unusual reaction occurring in the capsule during the heating phase. A further study is planned, involving a new method of preparation for the aged acrylate coating samples.
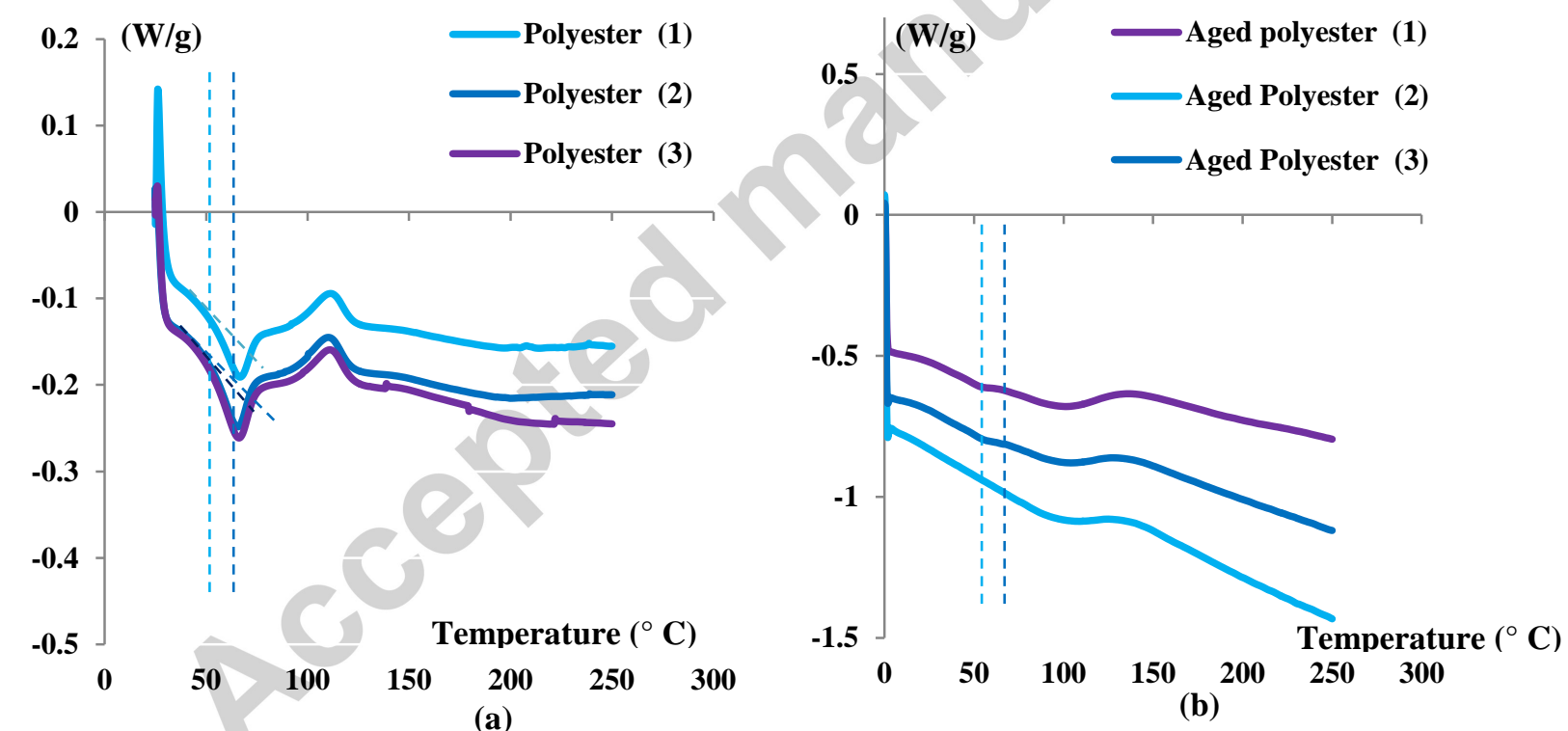

Figure 8. Hygroscopic ageing effect on the glass transition temperature.

In view of these results, we observe that the glass transition temperature remains the same regardless of its aged state or/and non-aged state.

\subsection{Evaluation of interfacial stress via the pull-out test}

We studied interfacial debonding stress of silica optical fibre/polyester (O.F./polyester) before and after hygroscopic aging by using the single-fibre pull out test. Nevertheless, several samples broke either at the level of the free part of the optical fibre or at the fibre/sample 
junction (fibre output). We have not included these measures in the interfacial debonding analysis. Figure 9 shows the force-displacement curves of the O.F./polyester sample obtained via pull out-test before ageing.

The force-displacement curves of the O.F./polyester system exhibit a linear elastic portion up to $\mathrm{F}=2 \mathrm{~N}$, followed by a continuous force decrease. In this specific case, the decline of force might be controlled by the friction on the total embedding length of the optical fibre (Figure 9).

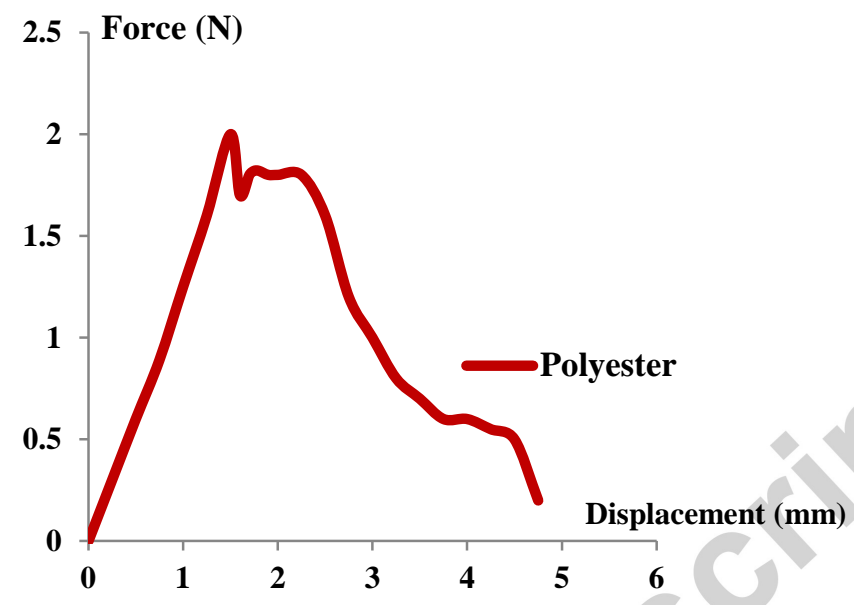

Figure 9. Force-displacement curves of the un-aged O.F./Polyester sample obtained owing to pull-out tests.

Figure 10 shows the force-displacement curves of the aged O.F./polyester samples obtained via pull-out tests. Five samples have undergone the characterisation process. All obtained curves exhibit a linear elastic portion, evolving to a maximum, followed by a continuous or discontinuous decrease of the measured force (Figure $10 \mathrm{~b}$ ). Contrary to the other specimens, sample number 2 deforms elastically up to $\mathrm{F}=3 \mathrm{~N}$, thus 3 times higher than the maximum value attained in the reproducibility tests (Figure 10 a). The force-displacement curves obtained on samples 3, 7 and 9 exhibit the classical 3 parts described previously in paragraph 2.5.2. As a consequence, for these specimens the force decrease appears to be controlled by the friction that takes place on the total embedded length of the optical fibre. Unfortunately, the force value of the sample number 2 is so great that it minimises the scale for the other specimens and does not enable the clear visualisation of the three steps of the forcedisplacement curve. For this purpose, the force-displacement curve of sample number 2 was shown in a separate graph (Figure 10. a). Force-displacement curves of sample number 5 don't highlight any friction between the fibre and resin during the extraction. Most of the time, the maximum force value undergone by the studied samples (except sample $n^{\circ} 2$ ) is weaker than $1 \mathrm{~N}$. Compared to the un-aged samples (figure 9), which could reproducibly withstand a maximum force of around $2 \mathrm{~N}$, the ultimate strength of the optical fibre polyester resin interface is strongly affected by hygroscopic aging. Moreover, the effect induced by hygroscopic aging yields a strongly wide overall response of the material, according to the variability of the force-displacement curves drawn on figure 9. Such a strongly variable macroscopic behavior might result from lower scale effects, such as interface weakening or fibre-matrix partial debonding having occurred during the hygroscopic aging process. Since damage occurs at the microscopic scale, a lesser reproducibility of the results is expected. 


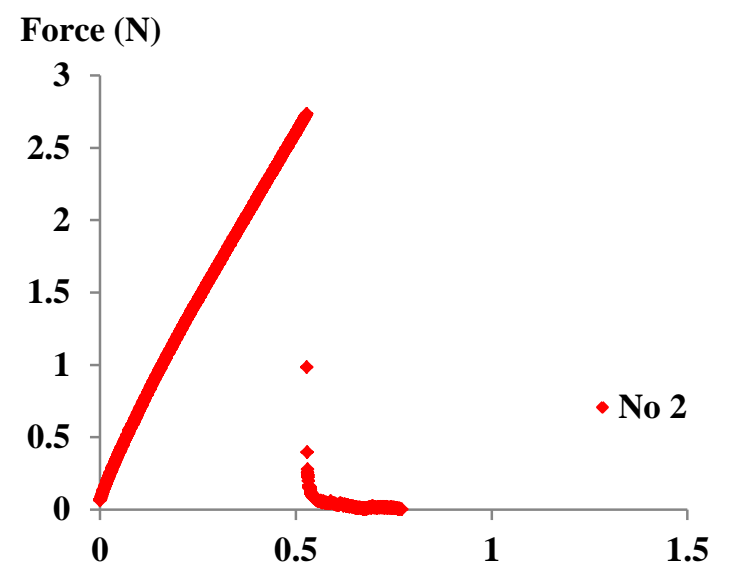

(a)

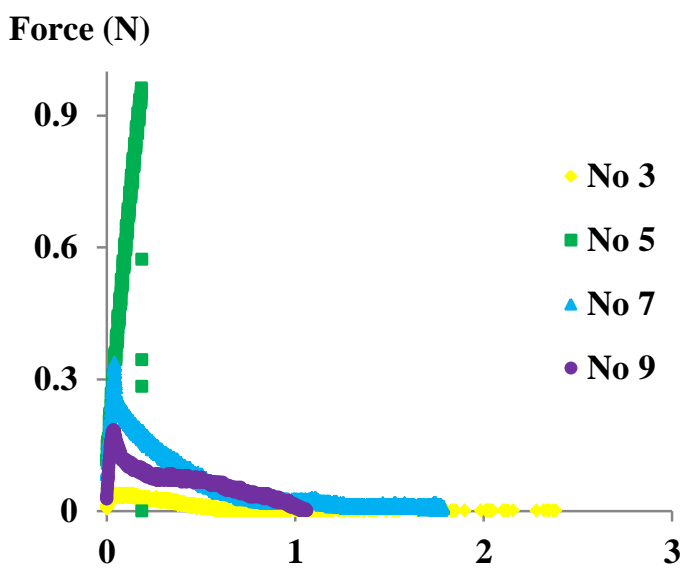

(b)

Displacement (mm)

Figure 10. Force-displacement curves of the aged O.F./Polyester samples obtained during pull-out tests performed under reproducibility conditions.

The values of F.O./polyester samples interfacial shear strength $\left(\tau_{d}\right)$ determined according to Eq. (4) from the experiment performed on un-aged samples are reported in Table 3.

Table 3. Interfacial shear stress values of O.F./polyester samples before and after ageing.

\begin{tabular}{|c|c|c|c|c|}
\hline \multirow[b]{2}{*}{ Sample \# } & \multicolumn{2}{|c|}{ Un-aged } & \multicolumn{2}{|c|}{ Aged } \\
\hline & Force $(\mathbf{N})$ & $\tau_{d}(\mathbf{M P a})$ & Force $(\mathbf{N})$ & $\tau_{d}(\mathbf{M P a})$ \\
\hline 1 & 2.00 & 2.96 & 3.03 & 3.86 \\
\hline 2 & 3.99 & 2.15 & 0.04 & 0.10 \\
\hline 3 & 3.40 & 2.86 & 0.96 & 1.46 \\
\hline 4 & 5.91 & 3.66 & 0.34 & 0.55 \\
\hline 5 & 9.04 & 3.13 & 0.18 & 0.31 \\
\hline Average & & 2.95 & & 1.26 \\
\hline $\begin{array}{c}\text { Std } \\
\text { deviation }\end{array}$ & & 0.54 & & 1.54 \\
\hline
\end{tabular}

We find that the values of interfacial shear strength $\left(\tau_{d}\right)$ for these specimens are scattered but significantly weaker after immersion than the corresponding values obtained on un-aged samples. This is more obvious with the graph of figure 11:

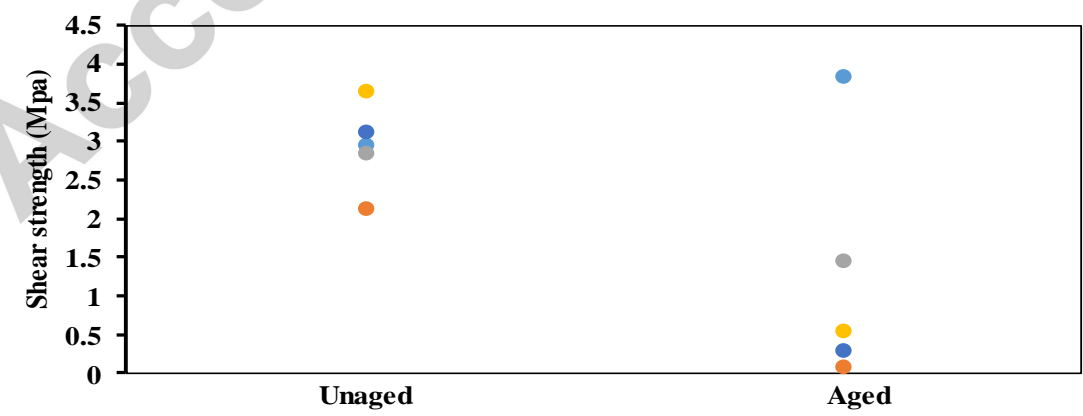

Figure. 11. Interfacial shear stress values of O.F./polyester samples before and after ageing.

As a consequence, hygroscopic aging reduces the interfacial adhesion between the optical fibre and the surrounding polymer. This shows that O.F./Polyester interfacial adhesion is strongly influenced by the presence of the water due to the process of moisture diffusion. This 
outcome could be explained by the physico-chemical modification of the interface in the presence water. Actually, plasticisation of the polymer matrix interface may significantly impair both its mechanical stiffness and ultimate strength.

According to Table 3, the hygroscopic aging has an important effect on the strength of the optical fibre / polyester interface. In the view of the results of paragraph 3.3, where we evaluated the influence of hygroscopic aging on the glass transition temperature of the polyester resin, we could explain this phenomenon by the relatively low $T_{g}$ of polyester. In fact, the polyester debonding stress in its aged state is strongly reduced, because the $T_{g}$ of the polyester is relatively low. These results are in agreement with the results described in paragraph 3.2. Actually, beyond $40^{\circ} \mathrm{C}$ the temperature is very close to the $T_{g}$ of polyester. Consequently, a decrease of the mechanical properties of the fibre/resin interface does occur in the case of the polyester based system, after exposure to an ambient fluid. This was confirmed by the lower value of the maximum force required to pull out the optical fibre from the O.F./polyester system in its aged state compared to the un-aged samples.

\section{Conclusions and perspectives}

In this work, the hygroscopic strains experienced by composite samples immersed in deionized water were followed from the transient to the permanent stage of the diffusion process. The measurements were carried out using Fibre Bragg Grating (FBG) sensors. The thermal strains, due to the temperature change, occurring during the investigation have been determined in order to achieve a more realistic estimation of the hygroscopic strains. In this study we found that the hygroscopic aging does not affect the glass transition temperature of polyester resin, according to Differential Scanning Calorimetry (DSC) analysis. However, the hygroscopic aging influences the interfacial adhesion of the O.F./Polyester system. In fact the influence of hygroscopic aging on the interfacial adhesion of O.F./resin reveals that the moisture diffusion degrades this interface from a physico-chemical standpoint. We found that the interfacial shear strength of aged O.F./Polyester system considerably decreases because of the lower glass transition temperature of the polyester. We can conclude that the drop in the Bragg wavelength $\left(\lambda_{b}\right)$ of glass/polyester composites in their saturated state should rather be associated with a decrease in their debonding strength $\left(\tau_{d}\right)$ due to moisture absorption.

\section{References:}

[1] Hollaway, L.C., A review of the present and future utilization of FRP composites in the civil infrastructure with reference to their important in-service properties, Constr. Build. Mater., 2010, 24: 2419-2445.

[2] Post, N.L., Riebel, F., Zhou, A., Keller, T., Case, S.W., Lesko, J.J., Investigation of 3D Moisture Diffusion Coefficients and Damage in a Pultruded E-glass/Polyester Structural Composite, Journal of composite materials, 2009, 43: 75-97.

[3] Lin, Y.C., Chen, X., Moisture sorption-desorption-resorption characteristics and its effect on the mechanical behavior of the epoxy system, Polymer, 2005, 46: 11994-12003.

[4] Adams, R.D., Singh, M.M., The effect of immersion in sea water on the dynamic properties of fibrereinforced flexibilised epoxy composites, Composite Structure, 1995, 31: 119-127.

[5] Adams, R.D., Singh, M.M., The dynamic properties of fibre-reinforced polymers exposed to hot, wet conditions, Composites Science and Technology, 1996, 56: 977-997 
[6] Jacquemin, F., Fréour, S., Guillén, R., Analytical modeling of transient hygro-elastic stress concentrationApplication to embedded optical fiber in a non-uniform transient strain field, Compos. Sci. Technol., 2006, 66: 397-406.

[7] Neumann, S., Marom, G. , Free-volume dependent moisture diffusion under stress in composite materials, Journal of Materials Science, 21, 26-30, 1986.

[8] Sar, B.E., Fréour, S., Davies, P., Jacquemin, F., Coupling moisture diffusion and internal mechanical states in polymers-A thermodynamical approach, European Journal of mechanics A/Solids, 2012, 36: 38-43.

[9] Perreux, D., Suri, C., A study of the coupling between the phenomena of water, absorption and damage in glass/epoxy composite pipes, Compos Sci Technol, 1997, 57: 1403-1413.

[10] Weitsman, Y.J., Elahi, M., Effects of fluids on the deformation, strength and durability of polymeric composites-An overview, Mech. Time-Dependent Mater., 2000, 4: 107-126.

[11] Weitsman, Y.J., Guo, Y.J., A correlation between fluid-induced damage and anomalous fluid sorption in polymeric composites, Composites Science and Technology, 2002, 62: 889-908.

[12] Karalekas, D., Cugnoni, J., Botsis, J., Monitoring of hygrothermal ageing effects in an epoxy resin using FBG sensor: A methodological study, Composites Science and Technology, 2009, 69: 507-514.

[13] Mihailov, S.J., Fiber Bragg grating sensors for harsh environments, Sensors, 2012, 12(2): 1898-918.

[14] Kang, H.K., Ryu, C.Y., Hong, C.S., Kim, C.G., Simultaneous Measurement of Strain and Temperature of Structures Using Fiber Optic Sensor, Journal of Intelligent Material Systems and Structures, 2001, 12(4): 277 281.

[15] Giaccari, P., Dunkel, G.R., Humbert, L., Botsis, J., Limberger, H.G., Salathé, R.P., On a direct determination of non-uniform internal strain fields using fibre Bragg gratings, Smart Materials and Structures, 2005, 14(1): 127-136.

[16] Lai, M., Botsis, J., Cugnoni, J., Studies of hygrothermal degradation of a single fiber composite: An iterative approach with embedded optical sensors and numerical analysis, Composites Part B, 2014, 60: 577-585.

[17] Lai, M., Botsis, J., Cugnoni, J., Coric, D., An experimental-numerical study of moisture absorption in an epoxy, Composites Part A, 2012, 43: 1053-1060.

[18] Ramezani Dana, H., Casari, P., Perronnet, A., Fréour, S., Jacquemin, F., Lupi, C., Hygroscopic strain measurement by fibre Bragg gratings sensors in organic matrix composites - application to monitoring of a composite structure, Composites: Part B, 2014, 58: 6-82.

[19] Ramezani Dana, H., Perronnet, A., Fréour, S., Casari, P., Jacquemin, F., Identification of moisture diffusion parameters in organic matrix composites, J. Compos.Mater., 2013, 47(9): 1081-92.

[20] Pierron, F., Poirette, Y., Vautrin, A., A Novel procedure for identification of 3D moisture diffusion parameters on thick composites: theory, validation and experimental results, Journal of Composites Materials, 2002, 36(19): 2219-2243.

[21] Colpo, F., Humbert, H., Botsis, J., Characterization of residual stresses in a single fibre composite with FBG sensor,Composite Science and Technology, 2007, 67: 1830-1841.

[22] Bosia, F., Botsis, J., Facchini, M., Giaccari, P., Deformation characteristics of composite laminates-part I: speckle interferometry and embedded Bragg grating sensor measurements, Composites Science and Technology, 2002, 62(1): 41-54.

[23] Guemes, J.A., Menéndez, J.M., Response of Bragg grating fiber-optic sensors when embedded in composite laminates, Composites Science and Technology, 2002, 62(7-8): 959-966. 


\section{ACCEPTED MANUSCRIPT}

[24] Helan, R., Urban, F., Principle of Fiber Bragg Gratings Measurement. In: Proceeding of $30^{\text {th }}$ International Spring Seminar on Electronics technology (ISSE/30), Cluj Napoca, Romania, 2007.

[25] Broutman, L.J., Measurement of the fiber-polymer matrix interfacial strength, Interfaces in composites, STP 452, Philadelphia. American Society Testing Materials, 1969, 27- 41.

[26] Delobelle, B., Thiebaud, F., Chapelle, D., Perreux, D., Placet, V., Ferrière, R., Embedment of optical fibre into a composite structure, Proceedings of JNC 16, Toulouse, 2009.

[27] James, S.W., Dockney, M.L., Tatam, R.P., Simultaneous independent temperature and strain measurement using in-fibre Bragg grating sensors, Electronics Letters, 1996, 32(12): 1133-1134.

[28] Xu, M.G., Archambault, J.L., Reekie, L., Dakin, J.P., Discrimination between strain and temperature effects using dual-wavelength fiber grating sensors, Electronics letters, 1994, 30(13): 1085-1087.

[29] Rao, Y.J., Yuan, S.F., Zeng, X.K., Lian, D.K., Zhu, Y., Wang, Y.P., Huang, S.L., Liu, T.Y., Fernando, G.F., Zhang, L., Bennion, I., Simultaneous strain and temperature measurement of advanced 3-D Braided composite materials using an improved EFPI/FBG system, Optics and lasers in Engineering, 2002, 38(6): 557-566.

[30] Gu, W., Kampe, L., Lu, G.Q., Correlation of fiber pull-out strength and interfacial vibration damping techniques by micromechanical analysis, Journal of materials science letters, 1998, 33: 5731-5737.

[31] Ghorbel, I., Valentin, D., Hygrothermal effects on the physico-chemical properties of pure and glass fiber reinforced polyester and vinylester resins, Polymer Composites, 1993, 14: 324-333.

[32] Struik, L.C.E., Physical ageing of amorphous polymers and other Materials, Elsevier, New York and Amsterdam 1978.

[33] Davies, P., Mazéas, F., Casari, P., Sea water aging of glass reinforced composites: shear behaviour and damage modelling, Journal of Composite Materials, 2001, 35: 1343-1372.

[34] Castaing, P., Lemoine, L., Effects of water absorption and osmotic degradation on long term behavior of glass fiber reinforced polyester, Polymer Composites, 1995, 16(5): 349-356.

[35] Maurin, R., Perrot, Y., Bourmaud, A., Davies, P., Baley, C., Seawater ageing of low styrene emission resins for marine composites: Mechanical behaviour and nano-indentation studies, Composite part A, 2009, 40: 10241032. 